\title{
O ESTUDO DA EFICIENCIA DO TRANSPORTE POR CABOTAGEM NO BRASIL
}

\author{
F.H. Maegima ${ }^{1}$; L.B. Incirilo, ${ }^{1, *}$ M. V. Nascimento ${ }^{1}$ \\ 1 Faculdade de Tecnologia de São José dos Campos - Professor Jessen Vidal \\ Av. Cesare Mansueto Giulio Lattes, 1350 - Eugênio de Melo, São José dos Campos/SP, \\ CEP: 12247-014, Brasil. \\ Telefone: (12) 3905-2423 \\ *lorena.incirilo@fatec.sp.gov.br
}

\begin{abstract}
RESUMO: A cabotagem é a navegação que utiliza vias interiores e costeiras entre portos dentro do território nacional. O Brasil demonstra amplo potencial de crescimento nas operações portuárias, apesar de possuir baixa representatividade no mercado, em virtude da burocratização das atividades de fiscalização de mercadorias, falta de infraestrutura logística e congestionamento dos portos. O objetivo desse trabalho consiste em realizar uma análise de eficiência utilizando o modelo matemático DEA (Data Envelopment Analysis). Para isso foram levantadas informações sobre a movimentação de cargas por cabotagem dos anos de 2008 a 2017, quantidade de portos e extensão da área costeira entre os países da União Europeia e Brasil. Os dados foram coletados nos sites da Eurostat e ANTAQ. Dessa forma, o resultado desse trabalho demonstrou que o Brasil deve movimentar cerca de 300 mil toneladas ao ano para tornar-se eficiente na movimentação por cabotagem em comparação aos países da UE.
\end{abstract}

PALAVRAS-CHAVE: Cabotagem; DEA; Eficiência; Transporte Marítimo.

ABSTRACT: Cabotage is navigation that uses inland and coastal roads between ports within the national territory. Brazil has a large potential for growth in port operations, despite its low market representation due to the bureaucratization of goods inspection activities, lack of logistics infrastructure and port congestion. The objective of this study is to perform an efficiency analysis using the Data Envelopment Analysis (DEA) mathematical model. For this purpose, information on cargo handling by cabotage from 2008 to 2017, number of ports and extension of the coastal area between the countries of the European Union and Brazil were collected. Data were collected on Eurostat and ANTAQ websites. Thus, the result of this work showed that Brazil must move around 300 thousand tons per year to become efficient in cabotage movement compared to EU countries.

KEYWORDS: Cabotage; DEA; Efficiency; Sea transportation.

\section{INTRODUÇÃO}

O transporte de cargas por cabotagem diz respeito ao transporte via marítimo ou utilizando vias navegáveis interiores entre portos dentro do território nacional (CNT, 2013). O Brasil possui ampla extensão de costa marítima, mais de $7500 \mathrm{Km}$, o que demonstra um amplo potencial de crescimento nas operações portuárias, transporte marítimo de longo curso e serviços de cabotagem (CNT, 2006).

No entanto, o transporte marítimo brasileiro possui baixíssima representatividade no mercado internacional (LEOPOLDINO et al., 2018), em virtude da burocratização das atividades de fiscalização de mercadorias, falta de infraestrutura logística, congestionamento dos portos e tempo de liberação da carga. É necessário investir em obras de infraestrutura e melhoria nos serviços 
prestados pelos entes da cadeia logística para que a cabotagem ganhe em competitividade em relação a outros modais (CNT, 2013).

\subsection{Problema em Estudo}

O transporte de cargas no Brasil enfrenta diversos problemas, onde cerca de $60 \%$ concentra-se no modal rodoviário, segundo a CNT (2019). Além de registrar elevado custo operacional, o transporte rodoviário é conhecido como o mais nocivo ao meio ambiente, devido ao número de veículos circulando, segundo a política ambiental do Ministério de Transportes (2015).

Essa excessiva concentração de transporte de cargas no modal rodoviário, revela a disparidade da matriz de transporte brasileira, que utiliza apenas $14 \%$ da sua produção pelo modal aquaviário (PASSOS, 2005).

A cabotagem se torna extremamente relevante visto que pode diminuir ou eliminar os principais gargalos de movimentação de cargas no Brasil (TEIXEIRA et al., 2018).

\subsection{Relevância do Trabalho}

É cada vez maior o número de empresas que percebem que o transporte de cargas deve fazer parte das discussões e decisões estratégicas da organização. Um melhor sistema de transporte, conforme Ballou (2006), contribui para um aumento da competitividade no mercado, bem como garante a economia de escala na produção e, ainda, reduz os preços das mercadorias.

De acordo com Alfredini e Arasaki (2009) "para as distâncias continentais de transporte entre regiões do Brasil, em especial aquelas com potencial marítimo, é fundamental promover a sustentabilidade da navegação de cabotagem, gerando o aumento e a consistência para o serviço de distribuição".

\subsection{Objetivo do Trabalho}

Este trabalho tem como objetivo geral analisar a viabilidade da utilização da cabotagem no Brasil, para potencializar a competitividade econômica.

Para alcançar esse objetivo foram estabelecidos os seguintes objetivos específicos:

- Realizar pesquisa bibliográfica para embasamento do tema;

- Identificar as características da cabotagem no Brasil em: infraestrutura, demandas e movimentações;

- Levantamento estatístico para análise de dados utilizando a ferramenta analítica DEA (do inglês Data Envelopment Analysis), fazendo uma análise comparativa de eficiência do modal de cabotagem com países da União Europeia.

\subsection{Proposta Metodológica}

A natureza da pesquisa foi aplicada como básica, pois procura o progresso científico, sem necessariamente aplicá-los na prática segundo Marconi et al. (1996).

A pesquisa explicativa visa identificar os fatores que influenciam a ocorrência dos fenômenos em análise. Esta refere-se ao porquê das coisas segundo os resultados apresentados (UFRGS, 2009).

O método utilizado será de modelagem e simulação que constitui uma importante ferramenta para teste de alternativas e tomada de decisão (CEFET et al., 2009).

A abordagem será quantitativa, buscando investigar dados em uma análise ampla e nãomensurável ou quantificável. Segundo FONSECA (2002), "a pesquisa quantitativa recorre à linguagem matemática para descrever as causas de um fenômeno, as relações entre variáveis, etc.”.

\section{REVISÃO DA LITERATURA}




\subsection{Transporte Marítimo}

O sistema aquaviário é caracterizado por qualquer movimentação de cargas que utilize vias aquáticas. Pode-se dividir em marítimo (mares), fluvial (rios) e lacustre (lagos), sendo o mais comum, o modal marítimo, sendo subdividido em transporte de longo curso e navegação de cabotagem (DIAS, 2015 apud GONÇALVES, 2017).

Segundo Silva (2015), o transporte marítimo de longo curso refere-se a navegação entre portos brasileiros e estrangeiros, já a cabotagem refere-se ao transporte entre portos do mesmo país ou entre um porto costeiro e um fluvial.

Junior (2013) afirma que as principais características desse modal são:

- Cunho internacional: natureza desse modal;

- Capacidade: transporte de grandes volumes;

- Flexibilidade: possibilidade de usar embarcações de médio/grande porte;

- Versatilidade: navios apropriados a todo tipo de carga;

- Concorrência: grande parte do tráfego internacional encontra-se no regime de livre concorrência de fretes e outros serviços operacionais.

\subsection{Eficiência Portuária}

A maior parte do comércio internacional é realizado via transporte marítimo, por isso, com a globalização, os portos tornam-se fatores fundamentais para o desenvolvimento do comércio internacional de um país e, também, para a economia mundial (FALCÃO et al., 2012).

A falta de planejamento integrado fez com que os portos fossem instalando-se em regiões e localidades sem o devido entendimento. Outro fator que contribui para a precariedade dos portos é a falta de indicadores de desempenho confiáveis que descrevem a real situação dos portos e prejudicam o planejamento em médio e longo prazo (JÚNIOR et al., 2013).

Segundo Falcão e Correia (2012) é crescente a preocupação com a eficiência portuária porque ela influencia diretamente na competitividade e na eficiência da indústria do país.

Segundo Santos et al. (2018 apud MERK E DANG, 2012), "A eficiência portuária é importante indicador da performance de um porto e concluem que, quanto mais eficiente for o porto, menores serão os custos envolvidos e maior será a facilidade de importação e exportação de determinado país".

O Brasil tem se desenvolvido recentemente, mas ainda carece de melhorias no setor portuário. No Relatório de Competitividade Global (2012/2013) do Fórum Econômico Mundial, foi avaliada a qualidade da infraestrutura portuária de 144 países, e a infraestrutura portuária brasileira foi classificada na $135^{\mathrm{a}}$ posição, conforme Figura 1.

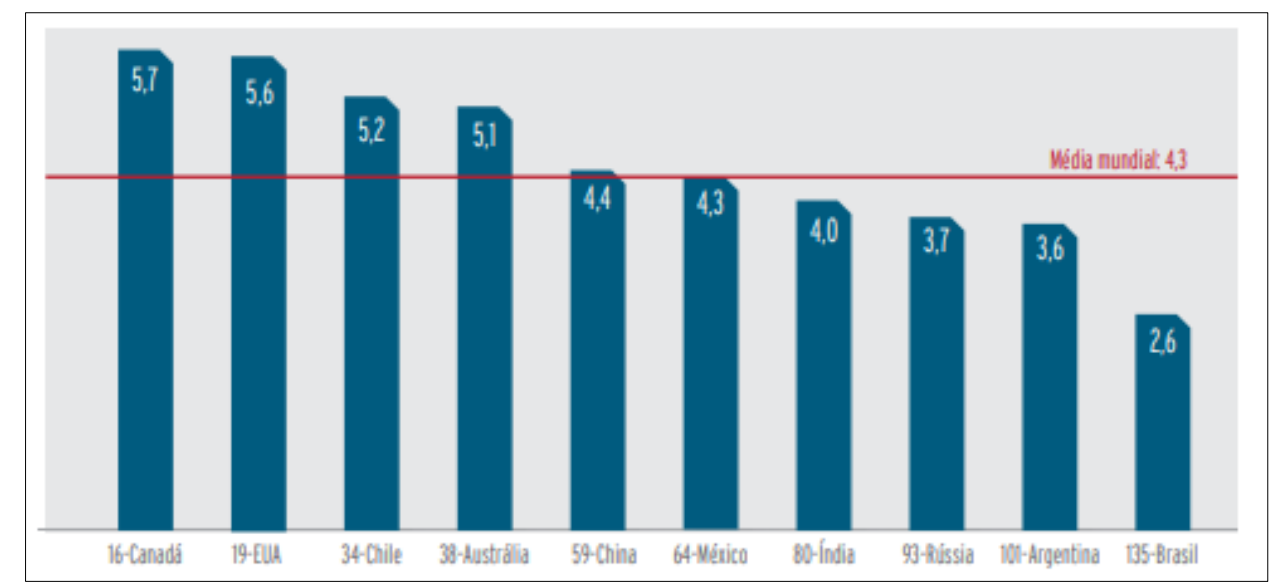

Figura 1. Avaliação da qualidade da infraestrutura portuária. Fonte: CNT (2012). 


\section{ISSN $2447-5378$}

\subsection{Sistema Portuário Brasileiro}

Em 5 de junho de 2013, foi editada a Lei ${ }^{\circ} 12.815$, para atender as necessidades proporcionadas pela expansão da economia brasileira, compreendendo um conjunto de medidas para impulsionar a modernização da infraestrutura e da gestão portuária, a expansão dos investimentos privados no setor, a redução de custos e o aumento da eficiência portuária, além da retomada da capacidade de planejamento portuária, com a reorganização institucional do setor e a integração logística entre modais, segundo o Ministério da Infraestrutura (2015).

Segundo dados do Boletim Estatístico da CNT (2019), o país conta com $41.795 \mathrm{~km}$ de vias navegáveis, sendo aproximadamente metade delas, $19.464 \mathrm{~km}$, vias economicamente navegadas, conforme exemplificado na Figura 2.

\begin{tabular}{|c|c|c|c|}
\hline \multicolumn{4}{|c|}{ AQUAVIÁRIO } \\
\hline \multicolumn{2}{|c|}{ Infraestrutura } & \multicolumn{2}{|c|}{ Frota Navegação Interior } \\
\hline Terminais de Uso Privado & 163 & Longitudinal de Carga & 2.468 \\
\hline Estação de Transbordo de Cargas & 28 & Passageiros e Misto & 152 \\
\hline Instalação Portuária de Turismo & 2 & Transporte de Travessia & 495 \\
\hline Portos Organizados & 35 & & \\
\hline \multicolumn{2}{|c|}{ Hidrovia - extensão em Km } & \multicolumn{2}{|c|}{ Frota Cabotagem/Longo Curso } \\
\hline Vias Navegáveis & 41.795 & Cabotagem/Longo Curso & 207 \\
\hline Vias economicamente navegadas & 19.464 & & \\
\hline
\end{tabular}

Figura 2. Estatísticas do modal aquaviário. Fonte: CNT (2019).

\subsection{Cabotagem no Brasil}

O Brasil apresenta extensa costa litorânea, mais de $7.500 \mathrm{~km}$ como apresentado anteriormente, criando condições vantajosas à cabotagem. A Figura 3 demonstra os principais portos da navegação de cabotagem.

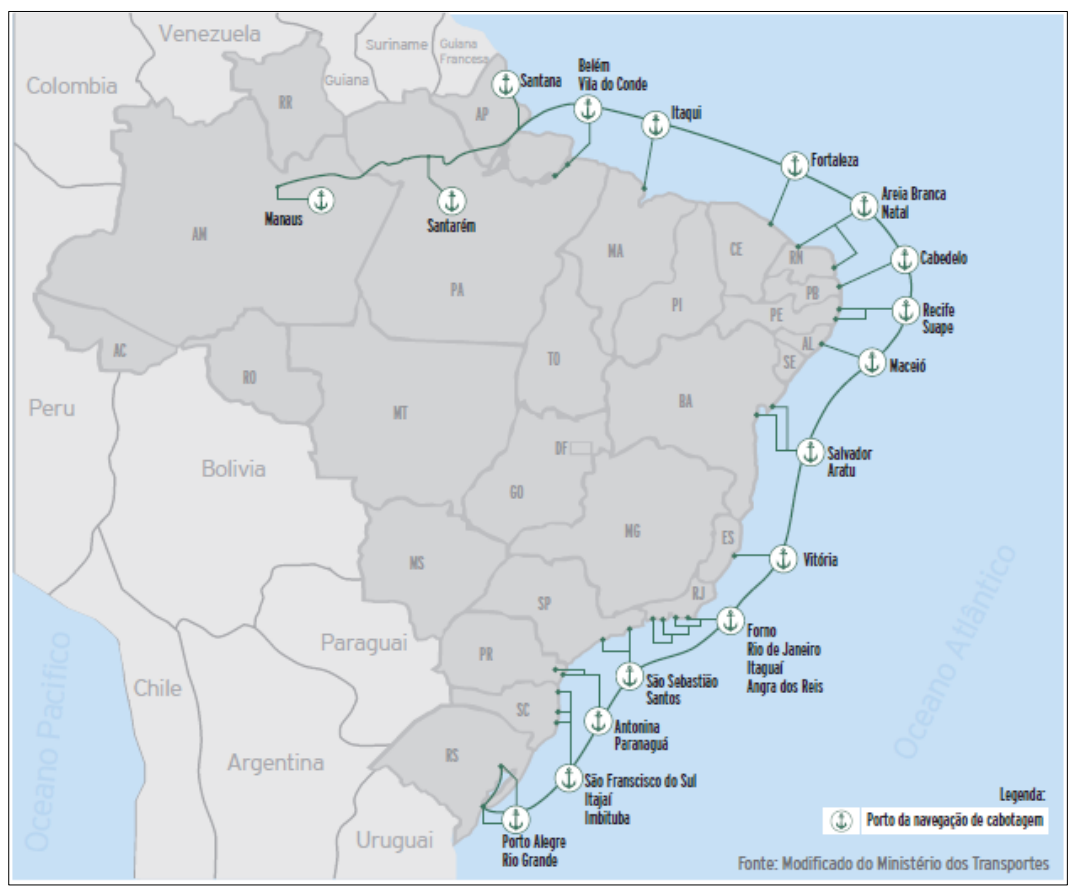

Figura 3. Portos da navegação de cabotagem. Fonte: CNT (2013). 
Dentre as principais vantagens deste modal podemos citar: grande capacidade de transporte de cargas, menor consumo de combustível, baixo número de acidentes, reduzido custo por toneladaquilômetro, além da menor emissão de gases poluentes CNT (2013).

A cabotagem no Brasil ainda enfrenta diversos entraves que dificultam o desenvolvimento do setor no país. Pode-se citar os elevados encargos sociais, a burocracia pública vigente, a falta de navios e contêineres, o alto custo do combustível, o tempo de espera nos portos e ausência de integração com outros modais (CNT, 2013).

Segundo BNDES (1997) citado por Vaclavik e Maçada (2009), no período anterior a década de 50, a cabotagem respondia por 27,5\% do total de transportes no Brasil. Após a abertura do país à indústria automobilística, a cabotagem jamais foi tão representativa quanto antes.

Segundo dados do anuário CNT do transporte de 2018, o setor movimentou 156,6 milhões de toneladas em 2017, volume 3,9\% superior a 2016, e 18,5\% superior a 2010, conforme Figura 4.

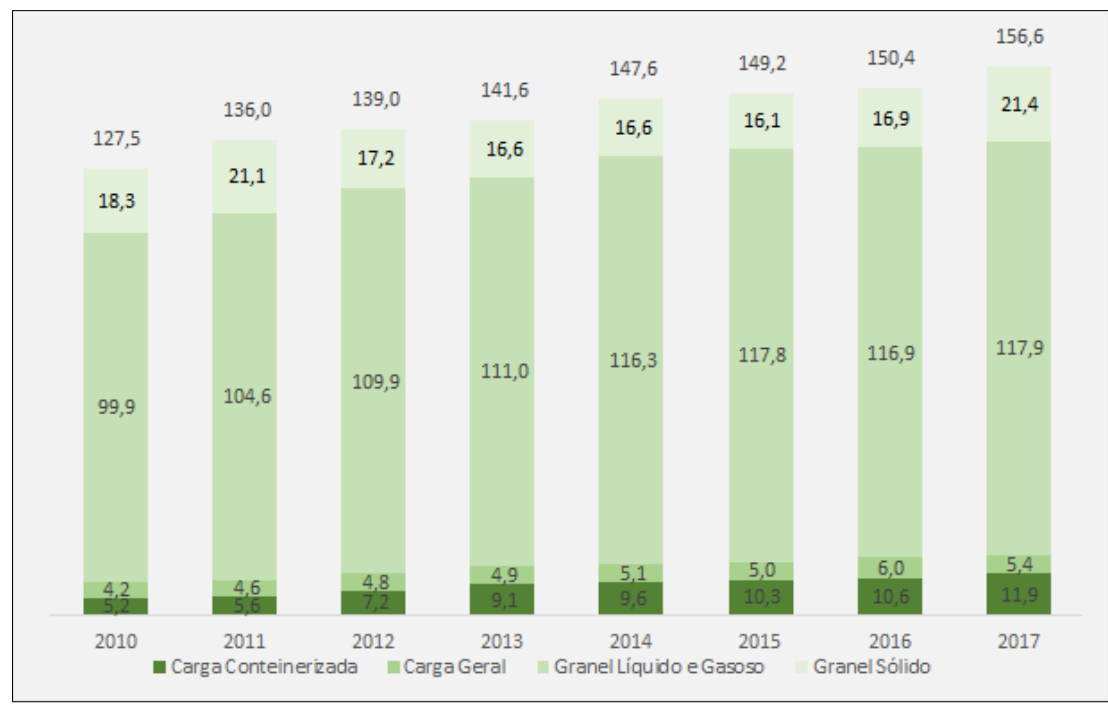

Figura 4. Volume de cargas movimentadas por cabotagem. Fonte: Os autores.

Além disso, os portos organizados que tiveram maior movimentação em 2017 foram: Santos/SP, Itaguaí/PR, Paranaguá/PR, Rio Grande/RS e Suape/PE, que concentraram cerca de 70\% do total de carga movimentada, em toneladas. Destaque para o porto de Santos que teve movimentação de 29,2\% das cargas movimentadas CNT (2018).

A importância da cabotagem no país foi constatada por Junior $(2015$, p.71) na afirmação de que:

"Fomentar a cabotagem é importante para racionalizar o setor de transportes no país, mitigar o Custo Brasil, aumentar a competitividade dos produtos nacionais, reduzir o preço final dos bens, arrefecer os congestionamentos de caminhões nos acessos dos principais portos marítimos brasileiros, impulsionar as redes e os fluxos de mercadorias, entre outros. Além disso, a expansão da cabotagem gera demanda na indústria naval brasileira, contribuindo, assim, com a geração de empregos e renda".

\section{RESULTADOS E DISCUSSÃO}

Foi realizado um levantamento estatístico nos sites da Eurostat (site oficial de estatística da União Europeia) e no site da ANTAQ (Agência Nacional de Transporte Aquaviário). Em ambos, buscou-se as informações sobre a movimentação anual de cabotagem de cada país em toneladas, no 


\section{ISSN $2447-5378$}

período de 2008 a 2017. Além disso, foram coletados os dados da área costeira e a quantidade de portos que realizam cabotagem em cada país.

\subsection{Análise de Dados e Modelagem Estatística}

De acordo com a série histórica elaborada, iniciou-se a análise dos dados e a construção do modelo de DEA proposto no trabalho. O range da série histórica de movimentação de cabotagem contemplou um período de 9 anos (2008 a 2017), coletados de forma anual. A Tabela 1 representa a área costeira em quilômetros e quantidade de portos que cada país possui.

Tabela 1. Área costeira e quantidade de portos dos países estudados.

\begin{tabular}{|c|c|c|}
\hline País & Área costeira (km) & Quantidade portos \\
\hline Bélgica & 67 & 4 \\
\hline Bulgária & 354 & 2 \\
\hline Dinamarca & 7.314 & 23 \\
\hline Alemanha & 2.389 & 16 \\
\hline Estônia & 3.794 & 5 \\
\hline Irlanda & 1.448 & 6 \\
\hline Grécia & 13.676 & 22 \\
\hline Espanha & 4.964 & 27 \\
\hline França & 4.853 & 18 \\
\hline Croácia & 6.268 & 5 \\
\hline Itália & 7.600 & 45 \\
\hline Chipre & 648 & 2 \\
\hline Letônia & 498 & 3 \\
\hline Lituânia & 90 & 2 \\
\hline Malta & 253 & 2 \\
\hline Holanda & 451 & 9 \\
\hline Polônia & 440 & 5 \\
\hline Portugal & 1.793 & 7 \\
\hline Romênia & 225 & 3 \\
\hline Eslovênia & 47 & 1 \\
\hline Finlândia & 1.250 & 19 \\
\hline Suécia & 3.218 & 27 \\
\hline Reino Unido & 12.429 & 41 \\
\hline Noruega & 25.148 & 23 \\
\hline Turquia & 7.200 & 22 \\
\hline Brasil & 7.500 & 29 \\
\hline
\end{tabular}

Fonte: Eurostat, 2019.

Após o levantamento das informações, foi feito a análise de correção entre as varáveis "áreas costeira", "quantidade de portos" e "volume médio de movimentação" ao longo do período estudado. A tabela 2 apresenta os valores de correlação. Observa-se que o tamanho da área costeira do país explica em $61 \%$ a quantidade de portos que um país possui, porém quando analisamos o volume médio transportado a correlação cai para $41 \%$. No caso do Brasil, pode-se afirmar que apesar da ampla extensão da costa marítima, o país tem baixa movimentação de cabotagem mesmo possuindo uma quantidade considerável de portos (29) que realizam tal serviço. 
Tabela 2. Correlação das variáveis.

\begin{tabular}{cccc} 
& Área costeira $(\mathbf{k m})$ & Qtd portos & Média \\
\hline Área costeira $(\mathbf{k m})$ & $100 \%$ & & \\
\hline Qtd portos & $61 \%$ & $100 \%$ & \\
\hline Volume médio & $41 \%$ & $81 \%$ & $100 \%$ \\
\hline Fonte: Eurostat, 2019. & & &
\end{tabular}

Essa afirmação é comprovada na análise de eficiência através do DEA que veremos posteriormente. É válido ressaltar que a análise foi feita com as três variáveis, do contrário, pode-se chegar a conclusões precipitadas sobre o país.

\subsection{Modelo DEA BCC Orientado à Output}

Os valores de eficiência foram obtidos através do modelo DEA BCC orientado à output. A Tabela 3 apresenta as variáveis de input e output selecionadas para análise.

Tabela 3. Variáveis selecionadas.

\begin{tabular}{|c|c|c|c|c|}
\hline \multirow[b]{2}{*}{ DMU } & \multirow[b]{2}{*}{ País } & \multicolumn{2}{|c|}{ Input } & \multirow{2}{*}{$\begin{array}{c}\text { Output } \\
\text { Média } \\
\text { movimentação }\end{array}$} \\
\hline & & $\begin{array}{l}\text { Área costeira } \\
(\mathbf{k m})\end{array}$ & $\begin{array}{c}\text { Qtd } \\
\text { portos }\end{array}$ & \\
\hline 1 & Bélgica & 67 & 4 & 128.578 \\
\hline 2 & Bulgária & 354 & 2 & 21.753 \\
\hline 3 & Dinamarca & 7.314 & 23 & 69.584 \\
\hline 4 & Alemanha & 2.389 & 16 & 171.828 \\
\hline 5 & Estônia & 3.794 & 5 & 25.923 \\
\hline 6 & Irlanda & 1.448 & 6 & 38.124 \\
\hline 7 & Grécia & 13.676 & 22 & 91.626 \\
\hline 8 & Espanha & 4.964 & 27 & 188.827 \\
\hline 9 & França & 4.853 & 18 & 182.097 \\
\hline 10 & Croácia & 6.268 & 5 & 13.730 \\
\hline 11 & Itália & 7.600 & 45 & 291.712 \\
\hline 12 & Chipre & 648 & 2 & 5.359 \\
\hline 13 & Letônia & 498 & 3 & 52.588 \\
\hline 14 & Lituânia & 90 & 2 & 30.833 \\
\hline 15 & Malta & 253 & 2 & 3.182 \\
\hline 16 & Holanda & 451 & 9 & 268.811 \\
\hline 17 & Polônia & 440 & 5 & 49.603 \\
\hline 18 & Portugal & 1.793 & 7 & 39.226 \\
\hline 19 & Romênia & 225 & 3 & 27.214 \\
\hline 20 & Eslovênia & 47 & 1 & 9.453 \\
\hline 21 & Finlândia & 1.250 & 19 & 90.364 \\
\hline 22 & Suécia & 3.218 & 27 & 147.206 \\
\hline 23 & Reino Unido & 12.429 & 41 & 317.701 \\
\hline 24 & Noruega & 25.148 & 23 & 147.433 \\
\hline 25 & Turquia & 7.200 & 22 & 254.774 \\
\hline 26 & Brasil & 7.500 & 29 & 197.324 \\
\hline
\end{tabular}

Fonte: Eurostat, 2019. 
A aplicação do modelo foi realizada por meio da ferramenta de análise Solver, do Microsoft Excel. Esse método permite a maximização de $\theta$ aplicando-se as equações de restrição (1), (2) e (3) descritas no Capítulo 3 e considerando as variáveis de inputs e outputs. As eficiências de cada país estão indicadas no Gráfico 1.

Gráfico 1. Eficiência das DMUs analisadas

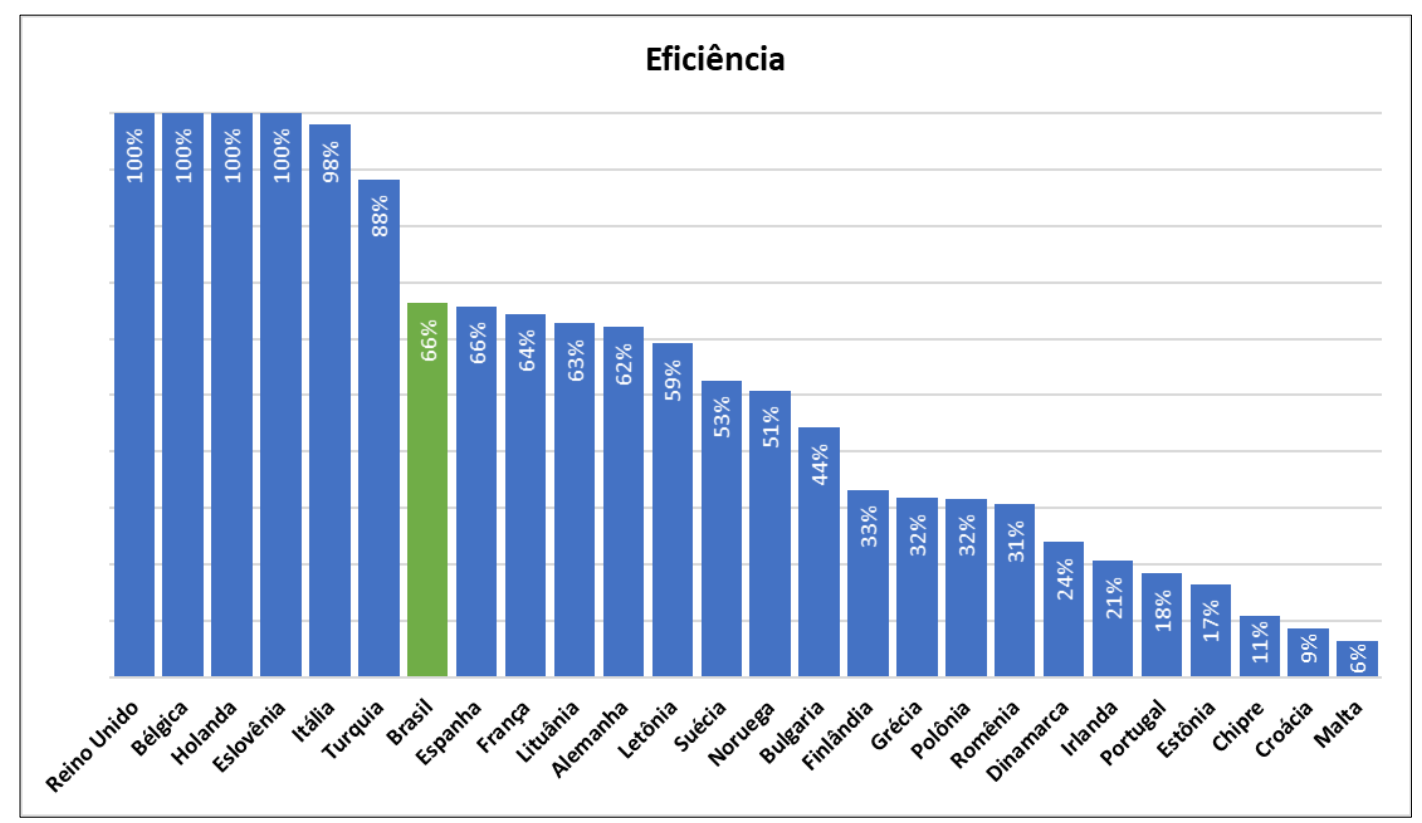

Fonte: Eurostat, 2019.

Das vinte e seis DMUs analisadas, quatro apresentaram eficiência de 100\%, Reino Unido, Bélgica, Holanda e Eslovênia. Esperava-se que o Brasil, devido à grande área costeira e a quantidade de portos, estivesse pelo menos próximo dos países mais eficientes, mas não é o que acontece. O país possui apenas 66\% de eficiência, o mesmo valor (ou próximo) de países como Espanha, França, Lituânia e Alemanha, que possuem área costeira e quantidade de portos inferiores ao Brasil, ou seja, o país tem baixa movimentação de cabotagem dadas as suas condições.

Dadas às condições de semelhança de área costeira, a Itália consegue atingir $98 \%$ de eficiência uma vez que possui maior quantidade de portos que fazem movimentação via cabotagem. A Turquia por sua vez, possui condição geográfica semelhante, apresenta $88 \%$ de eficiência com a diferença de 7 portos a menos que o Brasil e consegue movimentar 22,5\% a mais por ano em relação ao Brasil.

Portanto, o modelo BCC orientado à output indica que para o Brasil tornar-se um país eficiente e consiga viabilizar o uso da cabotagem no transporte de cargas no país, deve-se olhar como benchmarking os países $100 \%$ eficientes.

\section{CONCLUSÃO}

O objetivo proposto nesse trabalho foi alcançado. O modelo matemático demonstrou que o país deve movimentar cerca de 300 mil toneladas por ano para tornar-se eficiente, tomando como modelo os países da União Europeia. Neste presente trabalho foi possível analisar, estatisticamente, que o Brasil não possui uma boa colocação no quesito movimentação por cabotagem mesmo possuindo condições geográficas favoráveis e até mesmo grande quantidade de portos. 
Como extensão desse trabalho indica-se o estudo estatístico para entender onde é necessário obras de infraestrutura que contribuam para o escoamento de cargas de centros produtores até os portos para aumentar sua eficiência. Além disso, é necessário que os portos possuam infraestrutura que agilizem o processo de transbordo de cargas, visto que esse é um fator que contribui para o congestionamento nos portos.

Contudo, também é necessário um estudo dos custos envolvidos, que é diretamente relacionado com a infraestrutura, onde grande capacidade operacional de movimentação de cargas gera ganhos em escala que resultam em vantagens econômicas, como: menor consumo de combustível por tonelada transportada, menor custo por tonelada-quilômetro transportado, reduzido registro de acidentes, são fatores que podem afetar na decisão final do modal.

\section{REFERÊNCIAS}

AGÊNCIA NACIONAL DE TRANSPORTES AQUAVIÁRIOS. Estatísticas. Disponível em http://portal.antaq.gov.br/index.php/estatisticas/. Acesso em 15/05/2019.

AGUIAR, G. F.; AGUIAR, B. C. X. C.; WILHELM, V. E. Obtenção de índices de eficiência para a metodologia Data Envelopment Analysis utilizando a planilha eletrônica Microsoft Excel. Da Vinci. Vol. 1, n. 1, p. 157-170, 2006.

ALFREDINI, P. e ARASAKI, E. Obras e gestão de portos e costas. 2º edição, Editora Blucher, Mauá, 2009.

ANUÁRIO ESTATÍSTICO DE TRANSPORTE 2010-2017. Disponível em: http://transportes.gov.br/ultimasnoticias/7289-mt-lan\%C3\%A7a-anu\%C3\%A1rio-estat\%C3\%ADstico-2018.html. Acesso em 11/05/2019.

BALLOU, Ronald. H. Gerenciamento da Cadeia de Suprimentos/Logística Empresarial.

São Paulo: Bookman, 2006.

BEZERRA, P. R. C; ARAÚJO, D. M.; SILVA, D. R.; ALMEIDA, M. R. A Análise Envoltória De Dados (Dea - Data Envelopment Analysis) Como Ferramenta de Avaliação da Eficiência das MPES da Cadeia Produtiva do Petróleo e Gás do RN. Congresso Nacional de Excelência em Gestão, 2015.

CARLI, V. e DIAS, G. P. Cabotagem - Representatividade do Modal na Matriz de Transportes Brasileira. GEPRO - Grupo de Estudos de Produção. Vol. 6, 2016.

CONFEDERAÇÃO NACIONAL DO TRANSPORTE. Anuário CNT do Transporte Estatísticas Consolidadas. Disponível em http://www. http://anuariodotransporte.cnt.org.br/2018/Apresentacao. Acesso em 08/03/2019.

CONFEDERAÇÃO NACIONAL DO TRANSPORTE. Boletim Estatístico - Janeiro de 2019. Disponível em: https://www.cnt.org.br/boletins acesso em 09/05/2019.

CONFEDERAÇÃO NACIONAL DO TRANSPORTE. Pesquisa aquaviária CNT 2006. Portos marítimos: longo curso e cabotagem. Disponível em: http://www.cnt.org.br/Pesquisa/pesquisa-cnt-aquaviaria. Acesso em: 09/03/2019.

CONFEDERAÇÃO NACIONAL DO TRANSPORTE. Pesquisa CNT do transporte aquaviário. Disponível em: http://www.cnt.org.br/Pesquisa/pesquisa-transporte-aquaviario-cabotagem-2013 Acesso em: 09/03/2019. 
CONFEDERAÇÃO NACIONAL DO TRANSPORTE. Pesquisa CNT do Transporte Marítimo 2012 Brasília. Disponível

http://cms.cnt.org.br/Imagens\%20CNT/Publica\%C3\%A7\%C3\%B5es/Pesquisa\%20Maritima/Pesquisa\%20C NT\%20do\%20Transporte\%20Maritimo\%202012.pdf acesso em 09/05/2019.

CONFEDERAÇÃO NACIONAL DO TRANSPORTE. Plano CNT de Transporte e Logística 2018. Disponível em http://www.cnt.org.br/Paginas/plano-cnt-transporte-logistica. Acesso em 08/03/2019.

EUROSTAT STATISTICS EXPLAINED. Maritime Transport Statistics - Short Sea Shipping of Goods. Disponível em https://ec.europa.eu/eurostat/statistics-explained/index.php/Maritime_transport_statistics__short_sea_shipping_of_goods\#Total_short_sea_shipping. Acesso em 15/05/2019.

FALCÃO, V. A. e CORREIA, A. R. Eficiência Portuária: Análise das Principais Metodologias para o Caso dos Portos Brasileiros. JTL - Journal of Transport Literature, Vol. 6, n. 4, p. 133-146, Out. 2012.

FONSECA, J. J. S. Metodologia da pesquisa científica. Fortaleza: UEC, 2002. Apostila.

GONÇALVES, I. V. F., LOGÍSTICA AQUAVIÁRIA - MODAL DE CABOTAGEM: desafios e ganhos para o transporte no Brasil. JOÃO PESSOA, 2017.

JÚNIOR, J. N. C. S., JÚNIOR, E. F. N., PRATA, B. A. e MELLO, J. C. C. B. S. Avaliação Da Eficiência Dos Portos Utilizando Análise Envoltória De Dados: Estudo De Caso Dos Portos Da Região Nordeste Do Brasil. JTL - Journal of Transport Literature, Vol. 7, n. 4, p. 75-106, Out. 2013.

JUNIOR, N. F. F., O Setor Portuário e Marítimo Brasileiro: Avanços e Limitações. GEO FRONTER. Vol. 1, n. 1, p. 67-87, Jun.-Dez. 2015.

JUNIOR, N. M. S. Modal Marítimo Transporte de Produto Químico com Aplicação de Admissão Temporária. Os mais relevantes trabalhos de conclusão dos Cursos MBA's 2012. Vol. 11, n. 8, p. 778-833, 2013.

LEOPOLDINO, C. B; SOUZA, R. A.; Avaliação da cabotagem como opção de modal logístico: estudo de caso de uma metalúrgica nordestina. GEPROS. Gestão da Produção, Operações e Sistemas. Ano 14, no 3, p. 295-324, jul-set/2018.

MARCONI, M.D.A.; LAKATOS, E.M. Técnicas de pesquisas: Planejamento e execução de pesquisas, amostragem e técnicas de pesquisas, elaboração, análise e interpretação de dados. São Paulo, 1996.

MINISTÉRIO DA INFRAESTRUTURA. Histórico - Sistema Portuário Brasileiro. 2015. Disponível http://www.transportes.gov.br/sistema-portu\%C3\%A1rio.html Acesso em: 06/05/2019.

MINISTÉRIO DA INFRAESTRUTURA. Política Ambiental do Ministério dos Transportes. Disponível em: $\quad$ http://www.transportes.gov.br/conteudo/52-sistema-de-transportes/3183-pol\%C3\%ADticaambiental.html. Acesso em: 09/03/2019.

PASSOS, P. S. O. Logística de Transportes para o Desenvolvimento Nacional - A Visão do Governo Federal. São Paulo, 2005. Disponível em www.transportes.gov.br. Acesso em: 11/03/2019.

SANTOS, F. R., RIBEIRO, F. C. e NASCIMENTO, M. V. Impacto do Tipo de Carga nos Volumes de Exportação de um Porto: Estudo Aplicado no Porto de Itajaí. FATECLOG, 2018, Baixada Santista.

SILVA, K. S. LOGÍSTICA BRASILEIRA: um estudo teórico do modal aquaviário (cabotagem). JOÃO PESSOA, 2015. 


\section{ISSN $2447-5378$}

SILVEIRA, D. T.; GERHARDT, T. E. Métodos de pesquisa - Planejamento e Gestão para o Desenvolvimento Rural da SEAD/UFRGS. Porto Alegre, 2009.

TEIXEIRA, C. A. N; ROCIO, M, A, R; MENDES, A. P. A; OLIVEIRA, L. A. S. Navegação de Cabotagem Brasileira. BNDES Setorial 47, p. 391-436, 2018.

VACLAVICK, M. C e MAÇADA, A. C. G. Análise da Viabilidade da Utilização da Cabotagem: Um Estudo de Caso. ASSOCIAÇÃO NACIONAL DE PÓS-GRADUAÇÃO E PESQUISA EM ADMINISTRAÇÃO, 2009, São Paulo.

WORLD ECONOMIC FORUM. The Global Competitiveness Report 2012 - 2013. Disponível em https://www.weforum.org/reports. Acesso em: 15/05/2019.

YIN, R. K. Estudo de Caso - 5.Ed.: Planejamento e Métodos. Porto Alegre, 2015. 